\title{
Integral Monitoring System in Cases of Gender Violence VioGén System
}

Sistema de Seguimiento Integral de los Casos de Violencia de Género. Sistema VioGén

\author{
José Luis González Álvarez ${ }^{1,2}$ \\ Juan José López Ossorio ${ }^{1,2}$ \\ Carlota Urruela Cortés ${ }^{2}$ \\ Marina Rodríguez Díaz, Police Commissioner ${ }^{1}$ \\ (1) Ministerio del Interior, Gabinete de Coordinación y Estudios, Madrid, España. \\ (2) Universidad Autónoma de Madrid, Instituto de Ciencias Forenses y de la Seguridad, Madrid, España. \\ Email correspondencia: jlga@interior.es
}

\begin{abstract}
This paper discusses the normative origins, elements and operative foundations of the Integral Monitoring System in Cases of Gender Violence (VioGén System), a national government software application in Spain, implemented since 2007 to coordinate the actions of Spanish public professionals involved in the monitoring, assistance and protection of abused women and their minor children. Thousands of specialist users from the different integrated institutions access daily this application, which already manages more than 510,000 cases. The law enforcement part of the VioGén System is, for the time being, the most developed one, being the "police assessment of the risk of new violence" one of the main functionalities of the aforementioned system, for which two actuarial questionnaires have been developed (VPR and VPER). These questionnaires count with almost three million assessments; which consequently help in carrying out forensic, penitentiary and welfare assessments. Although the VioGén System currently only deals with cases of gender violence, in the future it may incorporate data on domestic violence, and technically it may be extended to the monitoring of other vulnerable groups.
\end{abstract}

Keywords: VioGén System, computer application, gender violence, intimate partner violence, VPR, VPER, risk assessment.

\section{Resumen}

Este artículo expone los orígenes normativos, los elementos y las bases operativas del Sistema de Seguimiento Integral de los Casos de Violencia de Género (Sistema VioGén), una aplicación de software gubernamental en España, implementada desde 2007 para coordinar las acciones de los profesionales públicos españoles involucrados en el seguimiento, asistencia y protección de las mujeres maltratadas y sus hijos menores. Miles de usuarios especialistas de las diferentes instituciones integradas acceden diariamente a esta aplicación, que ya gestiona más de 510,000 casos. La parte de aplicación policial del Sistema VioGén es, por el momento, la más desarrollada, siendo la "evaluación policial del riesgo de nueva violencia" una de las principales funcionalidades del sistema antes mencionado, para el cual se han desarrollado dos cuestionarios actuariales (VPR y VPER). Estos cuestionarios cuentan con casi tres millones de aplicaciones, lo que ayuda a realizar evaluaciones forenses, penitenciarias y de bienestar. Aunque el Sistema VioGén actualmente solo trata casos de violencia de género, en el futuro puede incorporar datos sobre violencia doméstica, y técnicamente puede extenderse al seguimiento de otros grupos vulnerables.

Palabras Clave: Sistema VioGén, aplicación de software, Violencia de Género, Violencia contra la pareja, VPR, VPER, valoración de riesgo. 


\section{GENDER VIOLENCE IN SPAIN}

Under Spanish law, Gender Violence is understood as the type of violence which conforms the manifestation of discrimination, the situation of inequality and the power relations of men over women, exercised over them by those who are or have been their spouses or who are or have been linked to them by similar relationships of affectivity, even without coexistence. So, it is worth noting that, in other countries this type of violence is understood as Intimate Partner Violence from male aggressors to female victims.

\section{THE VioGÉN INITIATIVE. NORMATIVE BACKGROUND}

The Integral Monitoring System in Cases of Gender Violence (VioGén System) is a computer application created by the Spanish Secretary of State for Security (SES) of the Ministry of Interior, which has been functioning continuously in Spain since July 26th, 2007. The system was created in the Office of Internal Security Studies (abbreviated to GESI in Spanish) of the SES to facilitate the fulfillment of the generic mandates of Articles 31 and 32 of the Organic Law 1/2004, of December 28th, regarding the "comprehensive protection measures against gender violence". Article 31.3 specifies that "the action of the Law Enforcement and Security Bodies shall take into account the Protocol of Action of the Security Forces and Coordination with the Judicial Bodies for the protection of domestic and gender violence". It was ordered, in turn (and among others), both the assessment of risk and the establishment of an agile system of information exchange, developing the necessary software applications. While Article 32 established that "public authorities shall elaborate collaborative plans that guarantee the organization of their actions in the prevention, assistance and prosecution of acts of gender violence, which shall involve health administrations, Administration of Justice, law-enforcement agencies (LEAs), social services and equality organizations ".

In compliance with the Organic Law 15/1999 of December 13th, regarding Protection of Personal Data, and the regulation that develops it (Royal Decree $1720 / 2007$, of December 21th), the VioGén System is protected in the file "Domestic and gender violence" referred to in Order INT/1911/2007, of June 26th (updated by Order INT/1202/2011, of May 4th). This Royal Decree regulates the personal data files of the Ministry of Interior, assigning the responsibility of this file to the SES, which may exercise the rights of access, rectification and cancellation. Within the SES, the management and operation of the file system VioGén currently corresponds to the Central Service of Gender Violence, of the Cabinet for Coordination and Studies (Royal Decree 770/2017 of 28th, July).

This file, which has the highest level of security, assumes the purpose of "improving the effectiveness in the protection of victims of domestic and gender violence; facilitating the monitoring of risk circumstances occurring in them; alerting of their evolution, allowing the adoption of appropriate protection measures; and preventing the risk of new aggressions". Thus, the intended uses are "the protection of victims, the prevention of criminal offenses related to domestic and gender violence, and the imprisonment of aggressors", pursuing as complementary aspects "statistical and welfare purposes".

Although the file "Domestic and gender violence" was foreseen as a guarantee to cover people who were victims and authors of events likely to be classified as domestic and gender violence (understanding 'authors' as the people involved in judicial proceedings and police investigations), currently it only contains data on gender violence, as defined on article 1 of the Law 1/2004: women who report being victims of violence by men who are or have been their partners. Since the reform of the Integral Law $1 / 2004$ operated by the Organic Law 8/2015, "regarding the modification of the protection system for childhood and adolescence", the possibility of adding identifying data of minors to the quantitative data that had already been recorded is being contemplated.

Also, Organic Law 4/2015, of April 27th, "of the Statute of the victim of crime", indicates that minors who are victims, as well as minors subject to guardianship and custody of female victims of gender violence, or people who are victims of domestic violence themselves shall be entitled to the assistance and protection measures provided for in Titles I and III of the mentioned Statute. Meanwhile, Article 282 of the Criminal Procedure Law, after the modification carried out by the first additional provision of the aforementioned Law 4/2015, of April 27 th, introduces the obligation of members of the judicial police to comply with the duties of information provided 
by the current legislation. Determining that they will carry out an assessment of the particular circumstances of the victims, this will provisionally determine what police measures should be adopted in order to guarantee them an adequate protection, without prejudice to the final decision that would the appropriate for the competent Court.

Other relevant national laws in this respect are the Organic Law 3/2007 "for the effective equality between women and men"; the "National Strategy for the eradication of violence against women 2013-2016" (which the System cited in measures 63, 64, 65, and 231); and the "Strategic Plan for Equal Opportunities 2014-2016", which in its $72 \mathrm{nd}$ measure stated, regarding the eradication of violence against women, the need to promote coordination "for the protection of victims of gender violence against women, through the Integral Monitoring System in cases of gender violence (VioGén System)".

In summary, the VioGén System is useful for (Zurita, 2013):

a) bringing together the different public institutions that have competences in gender violence;

b) integrating all the information of interest that is considered necessary, thus facilitating its exchange;

c) facilitating the assessment of risk of further violence occurring;

d) taking into account the risk level, facilitating monitoring and, if necessary, protection of victims, throughout the national territory;

e) helping the victim to draw up a "personalized security plan", with relevant self-protection measures within their reach; and, finally,

f) facilitating preventive work, issuing warnings, alerts and alarms, through a subsystem of automated notifications, when an incident or event is detected that could endanger the victim's integrity.

Although the VioGén System is established within the Secretary of State for Security of the Ministry of Interior, as it was precisely who first assumed the software developments and the development of the Law Enforcement part of the System. It should be taken into account that the System was created with the aim of integrality emerging from Law 1/2004 and serving the rest of the public institutions with competences in the fight against gender violence (such as justice, health, social services, and equality) as a main task to accomplish.

\section{THE VIOGEN SYSTEM}

\section{A. Data: description, system integration and exchange}

Technically, the VioGén System is based on a WEB application integrated in the Spanish SARA Network (Application Systems and Networks for Administrations), designed to have full compatibility, for navigation purposes, with the software browser Microsoft INTERNET EXPLORER version $10 / 11$ and with operating system Windows 7 Professional Service Pack 1. through the URL: https://viogen.ses.mir.es or https://10.11.200.154.

The gathered information refers to the commission of crimes related to gender violence: infractions and criminal records of the alleged perpetrators and their penitentiary situation, regarding the granting of permits or the release (probation or definitive) of the inmates who are subject to judicial measures, such as restraining orders or prohibition of communication with the victim. It contains identifying data, such as IDs/passports, as well as other identification documents, photographs, addresses, telephone numbers and email addresses. It also contains data of a personal nature: filiation, family, date and place of birth, gender, nationality, employment status, occupation, educational level and marital status. And finally, data regarding assistance and support to victims appears in the files prepared by the different services and bodies that support victims of gender violence, such as the type of help the victim receives, use of shelters, among others.

To comply with the purposes of the system of exchanging data with ease, the integration through web services with the Prison Information System (N-SIP) has been already achieved. Efforts are underway for a similar integration with the other penitentiary system (SISPE), with the different criminal information systems, such as SIGO and SIDENPOL, from the law enforcement field (Guardia Civil and National Police, respectively), and with the SIRAJ, from the judicial scope. Data is also currently exchanged with the Autonomous Police that do not directly use the VioGén System (Mossos d'Esquadra in Catalonia and Ertzaintza in the Basque Country) when the victims move their homes to territories under other LEAs.

At the same time, efforts are being made to integrate the social, welfare and equality services of the Autonomous Communities (through web services in the case that they have their own computerized systems); and it would also be possible to integrate any other service, 
such as health services. All of this would be done to prevent users from having to record the same data multiple times in different systems, which, in addition to leading to unwanted duplicities, can cause errors.

Along with the aim of integrality, taking into account that more than $25 \%$ of female victims are foreigners and the interest shown by various international delegations, several demonstrations of the system have been carried out in recent years to experts on violence against women in countries of our geographical and cultural environment. During the year 2016, a pilot test was carried out to connect outside our borders, through the Internet, with the Office of the Attorney General of the Dominican Republic, in a satisfactory manner.

Consequently, the intention is to establish a network of institutions, resources and information that allows monitoring and protection, in a quick, integral and effective way, of women and minors victims of gender violence, irrespective of their nationality and origin, at all times, and in any part of the national territory. Figure 1 shows the start screen of the system.

Figure 1. Starting page of the VioGén System.

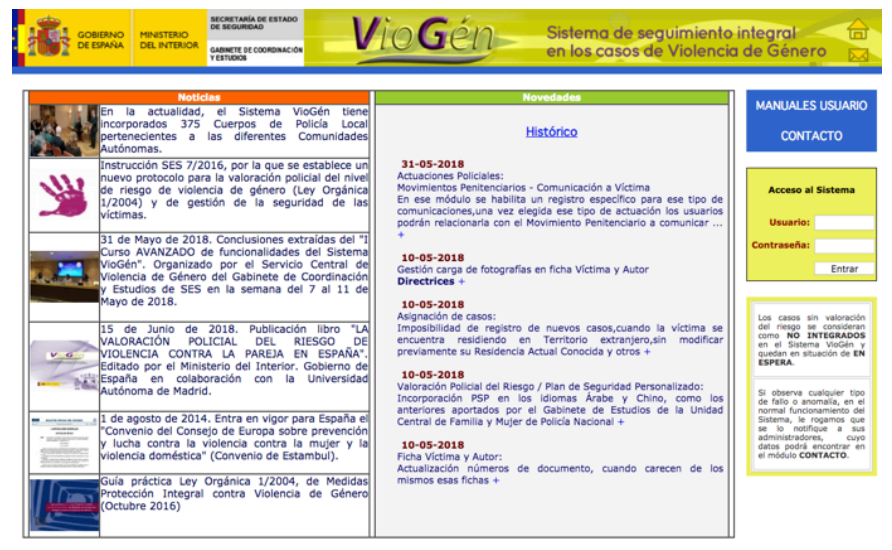

\section{B. Users of the VioGén System}

Normatively (Order INT / 1202/2011), the use of and access to the VioGén System is limited to:

a) members of the judicial branches of criminal order and Courts of Violence against Women;

b) the Public Prosecutor's Office;

c) specialists in judicial police and/or gender violence of the LEAs throughout the national territory (both at the state, regional, and local levels);

d) Penitentiary Administrations, through Directors of
Penitentiary Centers or through Centers of Social Integration;

e) members of the Coordination Units and Units of Violence against Women of the Delegations and Subdelegations of the Government (respectively);

f) the Integral Forensic Appraisal Units of the Legal Medicine and Forensic Sciences Institutes of the Ministry of Justice, and those of the Autonomous Communities;

g) Welfare Services, coordination points for protection orders for domestic and gender violence, and Offices for crime victims of the Autonomous Communities; and

h) Social Services of local entities, with protection competencies for victims of domestic or gender violence in their territory. All of them are able to introduce and modify data, in relation to the subjects of their competence and in their territorial scope.

At the time of preparing this report, close to 30,000 users have their access to the system enabled (see Table 1), although (fortunately) they do not access at the same time: the number of simultaneous work sessions that the system usually maintains during peak demand times moves in the range of 800 to 1,000 users.

Table 1. Habilitated users of the VioGén System as to 31/07/2018.

\begin{tabular}{lc}
\hline \hline Law Enforcement Agency & Users \\
\hline Guardia Civil & 11.840 \\
\hline National Police & 4.906 \\
\hline Mossos d'Esquadra & 321 \\
\hline Policía Foral & 140 \\
\hline Attached Units of Galicia & 23 \\
\hline Penitentiary Institutions & 582 \\
\hline Coordination and Violence Units & 106 \\
\hline Social and Equality Services & 464 \\
\hline Ministry of Justice & 3.890 \\
\hline C.G. del Poder Judicial & 4.469 \\
\hline Total & 29.235 \\
\hline \hline
\end{tabular}

As in any information system in which personal data is collected, in compliance with the Organic Law on Data Protection (15/1999), users access the system with a username and a personal and non-transferable key that allows the auditing of their activities, but has limitations, both in terms of the information that they can access and the functionalities they can activate. Each one has a specific profile, with different levels of privileges. These 
measures also comply with the recent European General Data Protection Regulation.

To both protect and monitor victims, communications between users with their administrators must be very fluid. This is achieved within the system itself through a "requirements module", through which the warnings, doubts, or suggestions that appear, are raised and answered hierarchically.

In order for the users to be able to use the System efficiently, different Manuals and Procedure Guides are available in the System for each of the modules and functionalities (see below). Moreover, the SES provides training activities that are compulsory (in person or via videoconference), both for existing users and for new users, moving the components of the Central Service to the territories that require it. Through these training activities, the aim is to bring users from different institutions together, facilitating interaction between them, and collating suggestions that allow the System to be refined and perfected.

\section{What is understood as a "case"?}

The VioGén System contains "cases of gender violence". A single case contains all the information that relates a victim to a single aggressor, so that, if a woman over time becomes a victim of gender violence of more than one offender, there will be a different case for each of her aggressors. The same procedure is set in place when an offender mistreats different women. Cases will always outnumber people.

At the moment, only LEAs can register cases in the VioGén System, but this does not discard the possibility that, in the future, other users could do it. Likewise, each case is automatically assigned to a specific police unit, which will be responsible for monitoring it, based on the victim's address, and that unit will be the only one that can modify any data of the case.

The cases contain, at least, a complaint and a fact associated with them, and can be found in different "situations". A situation is active when it is subject to police attention because its level of risk, depending on the time and circumstances surrounding it, evolves over time. A case is inactive when it no longer needs to be subject to police attention, and can be reactivated at any time. Finally, a case is considered to be of 'low risk' when it is cancelled due to one of the following causes:
- Firm acquittal of the accused.

- Dismissal of the proceedings of the investigated or processed.

- Firm conviction that has been executed in which the legal term for cancellation has elapsed.

The cases are registered or activated in the System at the time of a complaint. The case is assessed with the VPR questionnaire (Valoración Policial del Riesgo, see below) and the protection measures proportional to the resulting risk level are immediately assigned. The risk of gender violence is reassessed with the VPER (Vasloración Policial de la Evolución del Riesgo) questionnaires every time a significant incident occurs (such as a new complaint), or in predetermined periods of time.

In this process of risk reassessment, the indicators usually point out that the risk decreases, until there is no reason to think that recidivism will occur, at which time agents can turn off the case to "inactive". When legal assumptions for this are provided, the case becomes deregistered in the System in compliance with the rules for the protection of personal data, as in any other database. Naturally, if unfortunately, there is a new violent episode between the couple and a new complaint is made, the whole follow-up and police protection protocol is reactivated, as many times as deemed necessary.

There are a few cases that are "resistant to abandonment" in the System. In these cases, due to the dynamics of the relationship between the victim and the aggressor and their personal circumstances, the indicators of the risk assessment forms report that the risk is maintained over a significantly longer time than usual. Without a doubt, while it is estimated that there might occur some type of recidivism, follow-up and necessary protection of the victim will still be active.

Tables 2 and 3 show a summary of the System's activity.

Table 2. Cases included in the VioGén System from 26/07/2007 to $31 / 07 / 2018$

\begin{tabular}{ll}
\hline \hline Type of case & $\mathrm{N}$ \\
\hline \hline Active cases & 55.823 \\
\hline Inactive cases & 448.104 \\
\hline Discharged cases & 508 \\
\hline Foreign residents cases & 5.576 \\
\hline Total included cases & 510.011 \\
\hline \hline
\end{tabular}


Table 3. Analysed Risk Assessments from 26/07/2007 to $31 / 07 / 2018$

\begin{tabular}{ll}
\hline \hline Risk Assessments & $\mathrm{N}$ \\
\hline \hline VPR & 709.429 \\
\hline VPER & 2.595 .120 \\
\hline Total & 3.304 .549 \\
\hline \hline
\end{tabular}

Taking into account the country of origin of the victims (see Figure 2), of the active cases, $72.1 \%$ corresponded to Spanish citizens, $12.9 \%$ to women from Latin America, $8 \%$ to the EU, without accounting for Spain (highlighting Romania, with 50.3\%), and the rest to other regions of the world. To consult much more descriptive data in the System, the reader can go to the statistics pages of the Ministry of Interior's website, to the Doctoral Theses of Garrido (2012) or Zurita (2014), as well as López Ossorio and collaborators (2017).

Figure 2. Distribution of cases by country of birth of the victim as to $31 / 07 / 2018$

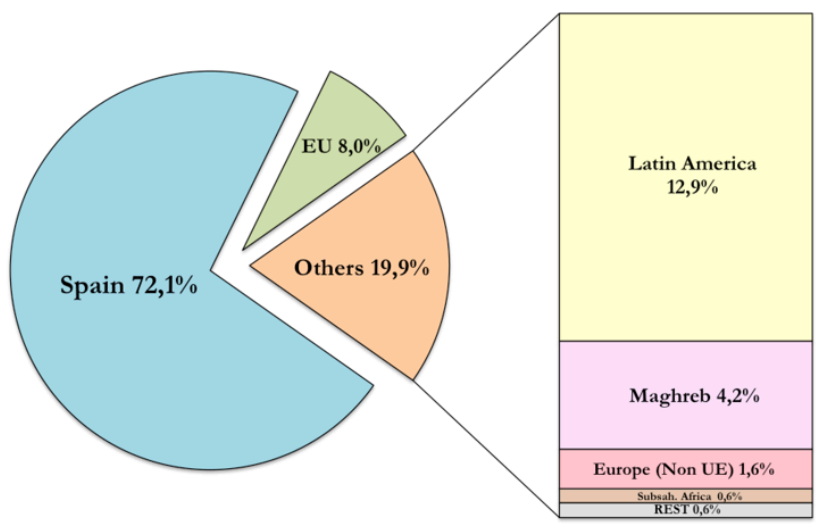

\section{Elements of the VioGén System}

Users navigate through the system in a very intuitive way, thanks to two search engines that facilitate the location of the cases, to allow a custom search of those involved, both at a national and territorial level. Once the case of interest is found, the System guides the user through a tab summary that he or she can access immediately being lead to all registered information. According to the needs of each user, specific modules to update data can be edited.

One of the great advantages of computerization is that the system helps with the automatic assignment of cases to the competent police units by reason of the residence of the victims. Also, it is necessary to emphasize that the subsystem of generation and distribution of automated notifications that, from a thirty management rules or individual/multiple causes (related to circumstances relevant to the safety of victims), automatically issues notifications to users, warning them of meeting deadlines, of changes of the situation, among others. This makes it easier for law enforcement officers to be up to date with the most relevant events.

In this sense, perhaps one of the most notable features to protect the victims is the technological tool of transmission of critical incidents, which facilitates the immediate exchange of information significant or urgent among the different specialists involved in the follow-up of a particular case. This module is aimed at the prevention of further violence, mainly directed to inform law enforcement users, who prior to the implementation of the actions that correspond have to confirm the veracity of the incident. In addition, it allows for the incorporation of multimedia elements, or any other document that is considered important, as well as selecting one or multiple recipients in addition to those initially defined by the system itself.

Without wishing to be exhaustive, other significant elements of the VioGén System are the statistical module; the subsystem of deceased victims as a result of gender violence; the functionality of the unification of cases; the user management module; and, finally, the modules for the efficient administration of the entities of the system (templates, units and districts).

\section{E. Law Enforcement Functions of the System}

It has already been mentioned that the law enforcement functions of the System are the most developed ones, and nowadays, local law enforcement agents oversee the cases. Other institutions have the right to access the System (according to their territorial competencies) and to issue communications about critical events.

With it being a computerized system, VioGén immediately manages all the information available and guarantees its accuracy. It also allows the sharing of the information with other specialists across the country.

All the trained National Police units and the Guardia Civil participate in the VioGén System. Regarding Autonomous Communities, Navarra's police force is integrated. The System interacts both with the Catalonian 
police force and the Basque police force, which is just starting to share their data. Both police forces have their own protocol of risk assessment and management. At a local level, more than 300 law enforcement forces are participating.

The VioGén System allows for the standardization of the police assessment of risk and the protection and preventive measures around the whole national territory. It means that all the victims receive organised police attention in order to avoid becoming a victim a second time. When a victim moves to a place where the VioGén System is not used (Catalonia and the Basque Country), their case is coordinated through specific protocols. In this way, no victim will be unattended. Furthermore, the system also protects women in a timeframe and in a way that is proportional to the risk of each individual victim.

\section{RISK ASSESSMENT}

In addition to helping in keeping all the victims' and aggressors' data up to date, the main law enforcement purpose of the VioGén System is to make risk assessments of women who reported that they were suffering from violence.

The traditional assessment based on the dangerousness of the offender has been questioned lately, since it tends to produce false negatives - dangerous subjects do not commit serious violent behaviors - and false positives - the subjects considered as not dangerous do commit serious violent behaviors -. In addition, the predictive capacity of the concept of dangerousness is limited, since it does not value other aspects of the reality of Intimate Partner Violence (IPV), such as the vulnerability of the victim and the specific situational context of the event (Andrés-Pueyo and Echeburúa, 2010).

Therefore, the VPR and VPER questionnaires follow the approach of risk assessment, taking into account both risk and protection indicators. Violence risk factors are considered those which increase the probabilities of a behavior taking place, being divided in two main groups: historical/static - such as gender - and dynamic - such as substance abuse - (Andrews and Bonta, 2010). On the other hand, protection indicators are those which determine the victim's exposition to risk indicators. Both types of factors have been taken intro account for the creation of the VioGén forms.

\section{A. Updating of the questionnaires}

In April 2014, three ministers related to gender violence (Interior, Justice and Health, Social Services and Equality) gathered to agree on the creation of a work group to oversee the "Risk Assessment Protocol". The new protocol would create a questionnaire in which the victim's and aggressor's employment situations, vulnerability factors and risk factors would be included (ones like disability, minority, care of minors). In compliance with this norm, a new multidisciplinary group of experts in gender violence from different law enforcement forces was formed. Some of these experts were psychologists who had been working for years in the training of law enforcement officers of the specialized units in this area (Equipos Mujer Menor from the Guardia Civil and Attention to Women Services from the National Police, UFAM), as well as academic experts who improved the two questionnaires previously developed in 2007.

Specifically, for the development of the two latest versions of the questionnaires (version 4.0; see below), an expert group from Universidad Autónoma de Madrid (UAM) and another group from the University of Barcelona (UB) were involved in order to analyze the suitability of the indicators for the questionnaires according to their professional opinions and the available scientific literature. Finally, a group of 10 experienced police officers in the field of IPV and risk assessment, where consulted about the adequacy of the indicators for the law enforcement assessment context. This process was designed to enhance the validity of content of the questionnaires.

For the development and validation of both the VPR4.0 and VPER4.0 forms (in its two versions), technical criteria and specific parameters advised for violence risk assessment tools in specialized literature were followed (Rice, Harris and Lang, 2013; Singh, 2013; Rossegger, Endrass, Gerth and Singh, 2014; Kropp, 2008).

As for its predictive validity, the VPR4.0 obtained an AUC (area under the curve) value of .658, and both versions of the VPER4.0 form got a value slightly over 80 . (López-Ossorio, 2017). These results are comparable to the ones reported in other national and international similar tools (Muñoz and López-Ossorio, 2016). 


\section{B. VPR4.0 and VPER4.0 questionnaires}

Law enforcement officers fill in the VPR4.0 when there is a new report. It is necessary to have enough and reliable information. The VPR4.0 questionnaire (Valoración Policial del Riesgo - Police Risk Assessment), has 39 items that provide information about the male offender and his interaction with the victim. These items are valued as "present" or "not present". The scores of the VPR4.0 items are obtained automatically ending with a given risk level, which, however, can be modified - never reducing the risk - by the officer who carried out the assessment. Risk levels are "unappreciated", "low", "medium", "high" and "extreme". Depending on the risk level set out, law enforcement agents immediately begin to take measures to safeguard the victim, and a period of time for the completion of the next risk assessment is stipulated (7/2016 SES Instruction). These reviews are performed consistently through the instrument VPER4.0. The VPER4.0 questionnaire (Valoración Policial de la Evolución del Riesgo - Police Risk Evolution Assessment), counts with 43 indicators (34 of risk and 9 of protection) to be assessed in the same way as the VPR4.0 questionnaire.

The aforementioned questionnaires have been modified (the first VPR had 16 indicators and the VPER 17) by taking into account social needs and legislative changes. These changes are due to the victim's and the aggressor's employment situations, the vulnerability of the victim (disability, whether they are a minor, or are responsible for minors), and risk factors. Moreover, relevant factors nowadays are: distinguishing the situations of especially vulnerable groups, the new technologies used, social networks, and, finally, gender violence that occurs in schools and between immature couples.

Law enforcement officers are still in charge of the risk assessment of any new violent incidents (according to established in 2007) and to apply the protection measures adapted to every level of risk. This measures have proven suitable to avoid a new violent incident against the victims (González y Garrido, 2015 a,b). It is expected that the new questionnaires distinguish better those victims in need of more protection, consequently reducing the relapse rate.

As an initial diagnosis, this questionnaire helps the police to establish the risk of a new episode of violence occurring in the short term. These law enforcement officers have special training in victim care and in risk assessment. If the report is made in court, it must be transferred to the appropriate police unit for them to update the case in the VioGén System. From here, the risk assessment is made.

During the monitoring of the victim's situation, the VPER $_{4.0}$ is filled in by the police units in charge of the victim's protection in order to keep the risk estimation updated so that it can be acted upon if/when necessary. The VPER4.0 can be filled in in two ways: the first way, "without any incidents", must be completed in a set timeframe (extreme level: before 72 hours, high level: before 7 days, medium level: every 30 days, and low level: every 60 days); whereas, the second, "with incidents", must be completed when a new violent episode or relevant circumstances take place. The VPER ${ }_{4.0}$ can also be filled in at the request of the court or the Public Prosecution.

The initial assessment, as well as any subsequent ones that involve a modification into a higher or lower level from the last risk assessment, are communicated to the judicial body and the Public Prosecution. Also, a report about the main risk indicators observed is communicated.

After determining a given risk level, protection measures are established (Compulsory and Complementary; attached in 7/2016 SES Instruction). These measures are designed to protect the integrity of the victim., becoming more intense as time and risk increase.

Even when the victim changes her physical location, she will still remain under police protection. As it has been mentioned, the current place of residence of the victim is one of the most relevant pieces of information in the System. This is an automatic process completed by the System, which determines the competent police unit according to the victim's residence and makes any suitable reassignment.

The risk assessment not only depends on a machine, as the System also allows police officers (the ones who are more familiar with each case due to having to thoroughly investigate them) to correct the automatic result of the risk assessment protocol when they have their own information that contradicts or improves it. It is impossible to introduce all the indicators in an accurate way into the machine, so the protocol does not try to replace police officers with a machine, but rather considers that the protocol is just a tool to improve their day-to-day work. The importance of professional experience is assumed in this situation, just as in any other profession. 
At the end of every assessment, the VioGén System sums up the results assigned to each case and requests for the conformity of the officer (which is usually high, 95\%; Zurita, 2014). By doing so, it allows the officer to show his or her disagreement and to establish the level of risk that they consider to be more appropriate. At the same time, the officer writes down observations, helping to perfect the System and both update and improve the training of other officers.

In this way, the Spanish protocol is the only one of its kind on an international level. Firstly, this is due to its complexity, having two questionnaires, one to establish the initial level of risk, and another to reassess this level of risk as time goes by. Secondly, due to its national implementation and its efficiency in obtaining the level of risk. And, finally, because it is developed on a computer system that allows thousands of users to connect to it at the same time. The Spanish questionnaires are actionoriented and have an automatic algorithm of correction that reduces the subjectivity of evaluators. Finally, this protocol goes beyond the risk assessment meaning the activation of protection measures is proportionate to each level of risk.

Since this protocol was created on July 31 st, 2018, 3,304.549 risk assessments have been made (709,429 VPR and 2,595.120 VPER). This fact lets us observe the magnitude of the VioGén System, merely proving that there are no other systems in the world that work with so many cases. Related to the level of risk, on July 31st, 2018, there were 55,823 active cases: 26,111 are classified as nonappreciate risk (46.77\%); $24.555(43.99 \%)$ are classified as having low risk; $4.956(8.88 \%)$ have medium risk; 188 $(0.34 \%)$ have high risk; and, $13(0.02 \%)$ are classified as having extreme risk. As this is an active system, this means that changes are constant, so this data presented only reflects the state of the risk assessment at the time of writing.

C. Complementarity between the police risk assessment and the forensic or penitentiary assessments.

During the construction and validation of the new forms of police assessment, contacts were established with professionals in charge of risk assessment in this area of violence against the couple by judicial requirement, belonging to the Institutes of Legal Medicine and Forensic Sciences (Psychologists and forensic physicians), the General Council of the Psychology of Spain, and the
Association of Forensic Psychologists of the Administration of Justice (APF), in case they could provide suggestions and useful indicators to the police from their perspective.

A major limitation of using the police for risk assessment is that agents cannot be asked to assess indicators which, being known to influence violent behavior, are out of their professional reach, such as those related to the presence of psychopathology or beliefs, attitudes, or cognitive distortions of aggressors and victims to justify this violence. So, the police's assessment of risk can never be perfect. This gap should be filled by other experts, such as penitentiary and forensic psychologists, who are trained to a much higher level than police officers in assessing any type of risk, especially the criminal conduct of the offender.

For both police officers and victims, it would be ideal to count with these professionals who could take care of the complete assessment of the risk of recidivism. This would mean deploying enough forensic psychologists throughout the country, as well as providing them with means so that they could face both the initial risk assessments, in all reported cases, and subsequent assessments, which allow knowing when to deactivate the protection measures.

Until this stage is reached, what is currently available from the VioGén System to facilitate the work of forensic psychologists is the possibility of consulting the assessment that the police agents made when these forensic psychologists are commissioned with making some expert report in this regard, as they can access the system from both the court and from the Institutes of Legal Medicine and Forensic Sciences.

The same could be said of the penitentiary field: although there is still a risk assessment procedure, like those of the VioGén System, after their interventions with convicted offenders (deprived from their freedom or enforcement measures in a less severe enforcement regime), penitentiary psychologists in charge of the System could provide valuable data to improve the protection of victims. 


\section{MANAGEMENT OF THE RISK OF RECIDIVISM: THE CUSTOM SECURITY PLAN}

Other significant developments of the new "law enforcement protocol for the assessment of the gender violence risk level (L.O. 1/2004) and the management of the safety of victims" (07/2016 SES Instruction) is that, in order to try to reduce the rate of recidivism, law enforcement shall ensure that victims are better involved with their own self-protection, helping them to implement the measures that they voluntarily agree to and are within their reach, without, in any way, impairing the proceedings for the protection the agents themselves are responsible for.

The security plans for the victims of intimate partner violence have been studied scientifically, both in the case of women (Murray, Horton, Johnson, Notestine, Garr, Marsh, Flasch and Doom, 2015) and the case of minors of which they are responsible for (Carter, Kay, George and King, 2003). They have been recommended by both international agencies (UNODC, 2010) as well as by independent organizations (WAVE, 2012). In addition to this, security procedures have already been put into practice in countries like Sweden (Belfrage, Strand, Storey, Gibas, Kropp and Hart, 2012; Storey, Kropp, Hart, Belfrage and Strand, 2014), the United Kingdom (ACPO, 2008), New Zealand (SNZ, 2006), Canada (Center for Children and Families in the Justice System, 2004), United States Department of Health and Human Services (2011), and even in Spain (for example, see the Municipal Points of the Regional Observatory of Gender Violence of the Municipalities of Valladolid and Madrid).

Based on references discussed in the previous paragraph, the most suitable measures for self-protection for women victims of gender violence and for minors who are dependent of these victims have been collected and incorporated in the annexes of instruction 7/2016, organized based on the risk levels estimates. At the end of 2017 , a total of 76,395 custom security plans had already been produced.

How does the VioGén System help with situations in which the victim resumes living with an abuser that she had previously reported? The police risk assessment protocol includes this type of behaviors as indicators in favor of the existence of risk and the need to maintain protection. It also helps agents to reliably detect this type of situation with automated notifications when the residences of victim and aggressor coincide.

Agents know that some victims may not be fully aware of the risks they run by keeping in touch with their aggressors and how victims may even hinder police protection efforts. So in these cases, extreme follow-up is imperative, carried out taking into account a delicate balance between the victim's right to privacy and not being "overwhelmed" by the police, and the police assurance that the victim's behavior puts her at risk.

Of course, it is not possible to protect those who reject full police protection, so in these cases, the participation of professionals from the healthcare field is of utmost importance. These professionals help informing the victims of the situation and encouraging them to collaborate, if that was the case.

Apart from the System, if the coexistence is resumed while a Restraining Order is in force, law enforcement proceeds to instruct the pertinent proceedings for that violation, reporting this to the judicial authorities, so that they adopt the measures deemed necessary.

\section{THE FUTURE OF THE VIOGÉN SYSTEM}

The VioGén System will be adapted to the regulations that changed with the entry into force of the Istanbul Convention on August 1st, 2014.

In addition, on June 17th, 2015, the UN issued a report on the situation of women in Spain, through the "Working Group on the question of discrimination against women in law and in practice", which made a series of recommendations to the Spanish Government, amongst which it requested the extension of the VioGén System "to consider all forms of violence against women".

More recently, in the National Agreement on the field of Gender Violence of the 12th Legislature, several proposals on the VioGén System and the Protocol of Police Risk Assessment were specified.

This system, as any computer system, is technically adequate for being expanded into the areas that are necessary. Currently, its contents are limited to cases of gender violence as it is foreseen in the Integral Law $1 / 2004$, but they could be extended to other vulnerable groups, such as the following, with the ultimate objective of protecting the most vulnerable as well as to develop specific security strategies, tailored to their needs: 
- Family and domestic violence.

- Abuse or abandonment of the elderly.

- Bullying.

- Harassment in the workplace.

- Human trafficking.

- Pedophilia.

- $\quad$ Missing persons.

- People with disabilities and their dependents.

- Hate crimes.

\section{REFERENCES}

ACPO. Association of Chief Police Officers. (2008). Guidance on investigating domestic abuse. Retrieved from http://library.college.police.uk/docs/npia/Domestic_Abuse_2008. pdf.

Andrés Pueyo, A., Echeburúa, E. (2010). Valoración del riesgo de violencia: instrumentos disponibles e indicaciones de aplicación. Psicothema, 22 (3), 403-409.

Andrews, D. y Bonta, J. (2010). The psychology of criminal conduct (5th ed.). New Providence, NJ: Lexis Nexis.

Belfrage, H., Strand, S., Storey, J.E., Gibas, A.L., Kropp, P.R. y Hart, S.D. (2012). Assessment and management of risk for intimate partner violence by police officers using the Spousal Assault Risk Assessment Guide. Law and human behavior, 36(1), 60.

Carter, L., Kay, S.J., George, J.L. y King, P. (2003). Treating children exposed to domes- tic violence. Journal of Emotional Abuse, 3, 183 202. doi: 10.1300/J135v03n03_02.

Centre for Children and Families in the Justice System. (2004). A Handbook for Police Responding Domestic Violence: Promoting Safer Communities by Integrating Research \& Practice. London, Ontario, Canada: Centre for Children and Families in the Justice System of the London Family Court Clinic.

Consejo General del Poder Judicial (España). Grupo de Expertos en Violencia Domés- tica y de Género (2016). Guía práctica de la Ley Orgánica 1/2004, de 28 de diciembre, de Medidas de Protección Integral contra la Violencia de Género. Retrieved from http://www.poderjudicial.es/cgpj/es/Temas/Violencia-domesticay-de-genero/Actividad-del-Observatorio/Guias-practicas/Guiapractica-de-la-Ley-Organica-1-2004--de-28-de-diciembre--deMedidas-de-Proteccion-Integral-contra-la-Violencia-de-Genero-2016-

Department of Health and Human Services. (2011). Safety Packing List. Office on Women's Health. US.

Garrido, M. J. (2012). Validación del procedimiento de valoración del riesgo de los casos de violencia de género del Ministerio del Interior de España [doctoral thesis]. Madrid: Facultad de Psicología, Universidad Autónoma de Madrid.
González, J. L. y Garrido, M. J. (2015a). Satisfacción de las víctimas de violencia de género con la actuación policial en España. Validación del Sistema VioGén. Anuario de Psicología Juridica, 25, 29-38.

González, J. L. y Garrido, M. J. (2015b). Utilidad de las medidas policiales de protección de víctimas de violencia de género en España. Opinión de los agentes. Cuadernos de la Guardia Civil, 51, 4161.

Kropp, P. R. (2008). Intimate partner violence risk assessment and management. Violence and victims, 23(2), 202-220.

López-Ossorio, J.J. (2017).Construcción y validación de los formularios de valoración policial del riesgo de reincidencia y violencia grave contra la pareja (VPR4.0 - VPER4.0) del Ministerio del Interior de España [doctoral thesis]. Madrid: Facultad de Psicología, Universidad Autónoma de Madrid.

López-Ossorio, J.J., González, J.L. y Andrés-Pueyo, A. (2016). Eficacia predictiva de la valoración policial del riesgo de la violencia de género. Psychosocial Intervention, 25, 1-7. doi: 10.1016/j.psi.2015.10.002.

López-Ossorio, J.J., González, J.L., Buquerín, S., García, L.F. y BuelaCasal, G. (2017). Risk factors related to intimate partner violence police recidivism in Spain. International Journal of Clinical and Health Psychology, 17, 107-119.

Muñoz, J.M. y López-Ossorio, J.J. (2016). Valoración psicológica del riesgo de violencia: alcance y limitaciones para su uso en el contexto forense. Anuario de Psicología Juridica, 26, 130-140. doi: 10.1016/j.apj.2016.04.005.

Murray, C.E., Horton, G.E., Johnson, C.H., Notestine, L., Garr, B., Marsh, A., Flasch, P. y Doom, E.B. (2015). Domestic violence service providers' perceptions of safety planning: A focus group study. Journal of Family Violence, 30, 381-392. doi: 10.1007/ s10896015-9674-1

Rice, M., Harris, G., y Lang, C. (2013). Validation of and revision to the VRAG and SORAG: the Violence Risk Appraisal Guide-Revised (VRAG-R). Psychological Assessment, 25(3). doi.10.1037/a0032878.

Rossegger, A., Endrass, J., Gerth, J., y Singh, J. (2014). Replicating the Violence Risk Appraisal Guide: A Total Forensic Cohort Study. Plos ONE, 9(3). doi:10.1371/journal.pone.0091845.

Singh, J. (2013). Predictive validity performance indicators in violence risk assessment: A methodological primer. Behavioral Sciences \&o the Law, 31, 8-22. doi: 10.1002/bsl.2052

SNZ. Standards New Zealand. (2006). Screening, risk assessment and intervention for family violence including child abuse and neglect, NZS 8006:2006, Wellington. Retrieved from http://www.police.govt.nz/sites/default/ files/publications/nzs8006-2006.pdf

Storey, J. E., Kropp, P. R., Hart, S. D., Belfrage, H., y Strand, S. (2014). Assessment and management of risk for intimate partner violence by police officers using the Brief Spousal Assault Form for the evaluation of risk. Criminal Justice and Behavior, 41(2), 256-271.

UNODC, United Nations Office On Drugs And Crime. (2010) Handbook on Effective Police Responses to Violence against Women. Criminal Justice Handbook Series. New York, United States. Retrieved from https://www.unodc.org/documents/justice-and-prison-

reform/Handbook_on_Effective_police_responses_to_violence_ag ainst_women_English.pdf 
WAVE. Women Against Violence Europe. (2012). Protect II. Competencias para la Evaluación del Riesgo y la Gestión de la Seguridad para la protección de Víctimas de Alto Riesgo. Women Against Violence Europe (WAVE), European Network and European Info Center Against Violence. Viena, Austria. Retrieved from http:// fileserver.wave-

network.org/trainingmanuals/PROTECTII_Risk_Assessment_and
_Safety_2012_Spanish.pdf

Zurita, J. (2013). La lucha contra la violencia de género. Seguridad y ciudadanía. Revista del Ministerio del Interior, 9, 63-127.

Zurita, J. (2014). Violencia contra la mujer. Marco histórico evolutivo y predicción del nivel de riesgo [doctoral thesis]. Madrid: Facultad de Psicología, Universidad Autonoma de Madrid. 